\title{
Effectiveness of Angioplasty in Treatment of Diabetic Foot Patients with Infragenicular Multiple Stenosis or Occlusion: A Prospective Study
} Ali Mahmoud Mohamed Galal*, Mohamed Ahmed Mohamed Ismail, Abdel Hady Mohamed Hussein

Vascular Surgery Department, Faculty of Medicine, Aswan University, Egypt

*Corresponding author: Ali M. M. Galal, Mobile: (+20)1001816078, E-Mail: a_mando76@yahoo.com

\begin{abstract}
Backgound: Diabetic foot is one of the most serious and debilitating consequences of diabetes, and it is described as an ulcerated foot in a diabetic patient with neuropathy and/or peripheral artery disease of the lower limb. Diabetic foot ulceration affects $4-10 \%$ of diabetic patients, with the condition affecting older patients more frequently.

Objectives: In this study, we aimed to assess the effectiveness of angioplasty in the treatment of diabetic foot patients with infragenicular multiple stenosis or occlusion.

Patients and Methods: We performed a prospective cohort investigation that recruited diabetic patient with infragenicular critical limb ischemia (CLI) with or without supragenicular lesion at Vascular Surgery Department in Aswan University Hospital through the period from January 2019 to June 2020. 20 patients were included if they were older than 18 years old, diabetic, had diabetic foot, and had confirmed diagnosis of CLI.

Results: Seventeen patients (85\%) had immediate success, they remained patent after one month. After three and six months, 14 patients $(70 \%)$ and $13(65 \%)$ remained patent, respectively ( $\mathrm{p}>0.05)$. With regard to limb salvage by the end of six months, 15 patients (75\%) had limb salvage in the form of rest pain relief in $3 / 4$ patients (75\%), minor ulcer healing in 10/10 patients (100\%), and healing of tissue after debridement or minor amputation 2/6 patients (33.3\%). The remaining five patients had non-salvaged limbs. As regarding amputations, three patients (15\%) underwent major amputation. A total of four patients (20\%) had complications.

Conclusion: In conclusion, infragenicular angioplasty exhibited efficacy in CLI management in diabetic patients, with an acceptable patency rate and safety profile.
\end{abstract}

Keywords: Diabetes, Diabetic Foot, Infragenicular Angioplasty, Limb Ischemia.

\section{INTRODUCTION}

Diabetic foot ulcers are common complications of diabetes mellitus (DM), affecting more than $15 \%$ of all diabetic patients during their lifetime ${ }^{(1)}$. It was estimated that about $15-20 \%$ of patients with such conditions would need an amputation ${ }^{(2,3)}$. The most significant risk factor for foot ulcers is peripheral sensory neuropathy, which is accompanied by peripheral vascular disease (PVD) ${ }^{(3)}$. PVD affects the arterial tree at all levels, but atheroma seems to prefer some locations, such as bifurcations where hemodynamic shear stress is low or flow separation occurs ${ }^{(4)}$. The infragenicular arteries are often involved in patients with diabetes, resulting in multiple stenosis or occlusion ${ }^{(5)}$. Patients with critical limb ischemia (CLI) are becoming older and sicker with the more complex distal disease.

Revascularization is mandatory for patients with evident peripheral ischemia because sufficient blood flow is essential for the healing of injuries and the resolution of the underlying infection ${ }^{(6)}$.

A surgical bypass is a popular form of treatment of ischemic limbs, which has recorded good long-term findings (7). In cases of multiple occlusions, revascularization is required at each stage to restore blood flow and raise the likelihood of limb regeneration (8). In combination with surgical bypass on the distal extremity, transluminal angioplasty of iliac arteries can be performed, and effectiveness has been demonstrated in diabetic patients. Transluminal angioplasty is also an ideal alternative for single stenotic injuries ${ }^{\left({ }^{(9)}\right.}$.
A large meta-analysis of 52 studies demonstrated the efficacy of angioplasty in managing infrapopliteal atherosclerotic lesions, with an overall success rate of $91.1 \%{ }^{(\mathbf{1 0})}$. In this study, we aimed to assess the effectiveness of angioplasty in the treatment of diabetic foot patients with infragenicular multiple stenosis or occlusion.

\section{MATERIAL AND METHODS}

We performed a prospective cohort investigation that recruited diabetic patient with infragenicular CLI with or without supragenicular lesion at Vascular Surgery Department in Aswan University Hospital through the period from January 2019 to June 2020. 20 patients were included if they were older than 18 years old, diabetic, had diabetic foot, and had confirmed diagnosis of CLI. We included patients with type B the Trans-Atlantic Inter-Society Consensus Document (TASC), defined as "multiple stenosis each equal or less than $5 \mathrm{~cm}$ in length with total length less than $10 \mathrm{~cm}$, or single occlusion equal or less than $10 \mathrm{~cm}$ in length $5 \mathrm{~cm}$ in the target tibial artery with occlusion or stenosis similar or worse in severity in the other tibial arteries".

The diagnosis of diabetic foot was based on clinical presentation and supporting imaging modalities (11). While the CLI was defined as Rutherford category of equal or more than four ${ }^{(\mathbf{1 2})}$. Patients were excluded if they had extensive lower limb infections, full-thickness gangrene, primary vascular etiology, and/or mental or 
cognitive impairment. Besides, we excluded patients who were not eligible for two revascularization strategies.

\section{Data Collection:}

The following data were obtained from every eligible patient:

- Demographic characteristics.

- Risk factors for CLI and diabetic foot

- History of previous peripheral artery disease (PAD) procedures or leg amputation.

- Findings of the physical examination.

- Routine laboratory findings.

- Imaging findings, including duplex ultrasound, computerized tomography angiography (CTA), magnetic resonance angiography (MRA), and digital subtraction angiography (DUS).

\section{Study Procedures:}

Patients were instructed to take clopidogrel five days preoperatively. Alternatively, a periprocedure loading dose of $300 \mathrm{mg}$ was administrated. The angioplasty technique was performed according to the institute's protocol and all procedures were performed under local anesthesia. The access through the artery was guided by preoperative imaging and done by either antegrade or cross-over techniques of common femoral artery puncture. Then, F sheath was inserted, and a dyeguided angiography was performed to identify the lesion. To cross the stenosis, guidewires were introduced and a drilling motion of the guidewire was performed, followed by insertion of coaxial catheter balloon. Then, a 2-3.5 $\mathrm{mm}$ balloons were inserted and inflated. After balloon deflation, a $100 \mathrm{ug}$ of nitroglycerin was injected intra-arterially. Then, an angiogram was performed. A success technique was defined as less than $30 \%$ residual stenosis of the target tibial artery and restoration of the pulse. Patients were managed postoperatively according to the institute's protocol and maintained on cilostazol $100 \mathrm{mg}$ twice/day, acetylsalicylic acid $150 \mathrm{mg} /$ day, and /or clopidogrel $75 \mathrm{mg}$ /day after hospital discharge. All patients were followed up for six months procedure.

\section{Study Endpoints:}

The primary endpoint in our study was the primary patency rate at the end of the sixth month of follow-up, the patency was determined by palpation of the pulse and Duplex ultrasound. The secondary endpoints included the rate of clinical success, limb salvage, rest pain restoration, and postoperative complications.

\section{Ethical consent:}

An approval of the study was obtained from Aswan University Academic and Ethical Committee. Every patient signed an informed written consent for acceptance of the operation. This work has been carried out in accordance with The Code of Ethics of the World Medical Association (Declaration of Helsinki) for studies involving humans.

\section{Statistical analyses}

The statistical analyses were employed using SPSS software (Statistical Package for the Social Sciences; SPSS Inc., Chicago, IL, USA) version 22 for Microsoft Windows. The mean \pm standard deviation $( \pm \mathrm{SD})$ and median were used to describe numerical variables. Frequencies with percentages were applied to present categorical variables. The level of significance was set at a probability critical value (p-value) lower than 0.05 .

\section{RESULTS}

The baseline data of the study are shown in table 1 .

Table (1): Baseline data in both groups

\begin{tabular}{|c|c|c|}
\hline \multirow[t]{2}{*}{ Variables } & \multicolumn{2}{|c|}{ Patients $(n=20)$} \\
\hline & No. & $\%$ \\
\hline \multicolumn{3}{|l|}{ Sex } \\
\hline Male & 15 & 75.0 \\
\hline Female & 5 & 25.0 \\
\hline \multicolumn{3}{|l|}{ Age (years) } \\
\hline Min. - Max. & \multicolumn{2}{|c|}{$52.0-82.0$} \\
\hline Mean \pm SD. & \multicolumn{2}{|c|}{$67.05 \pm 9.34$} \\
\hline Median & \multicolumn{2}{|c|}{67.0} \\
\hline Smoking & 14 & 7 \\
\hline Diabetes mellitus & 16 & 80 \\
\hline Hypertension & 15 & 75 \\
\hline Ischemic heart disease & 12 & 60 \\
\hline HLIP & 13 & 65 \\
\hline Stroke & 4 & 20 \\
\hline Previous angioplasty & 5 & 25 \\
\hline \multicolumn{3}{|l|}{ Rutherford } \\
\hline 4 & 4 & 20.0 \\
\hline 5 & 10 & 50.0 \\
\hline 6 & 6 & 30.0 \\
\hline Min. - Max. & \multicolumn{2}{|c|}{$4.0-6.0$} \\
\hline Mean \pm SD & \multicolumn{2}{|c|}{$5.10 \pm 0.72$} \\
\hline Median & \multicolumn{2}{|c|}{5.0} \\
\hline
\end{tabular}

Table (2): Amputations and complications in both groups

\begin{tabular}{|l|l|c|c|}
\hline Variables & \multicolumn{2}{|c|}{$\begin{array}{c}\text { Patients } \\
\text { (n= 20) }\end{array}$} \\
\cline { 3 - 4 } \multicolumn{1}{|c|}{ Amputation } & No & No. & $\mathbf{\%}$ \\
\cline { 2 - 4 } & Yes & 17 & 85 \\
\hline Complications & Major & 3 & 15 \\
\cline { 2 - 4 } & Acute thrombosis & $\mathbf{1}$ & $\mathbf{5}$ \\
\cline { 2 - 4 } & Severe hemorrhage & 0 & 0 \\
\cline { 2 - 4 } & Severe graft infection & 0 & 0 \\
\cline { 2 - 4 } & $\begin{array}{l}\text { Huge hematoma and } \\
\text { pseudo-aneurysm }\end{array}$ & 1 & 5 \\
\cline { 2 - 4 } & Minor & & \\
\cline { 2 - 4 } & Edema & $\mathbf{3}$ & $\mathbf{1 5}$ \\
\cline { 2 - 4 } & Infection & 0 & 0 \\
\cline { 2 - 4 } & Hematoma & 0 & 0 \\
\cline { 2 - 4 } & Contracture scar at knee & 0 & 0 \\
\hline
\end{tabular}


There were no significant associations between patency rate and age, risk factors, co-morbidities, symptomatic presentation, and lesion morphology. Patients with IHD and a history of previous angioplasty had significantly lower patency rate $(\mathrm{p}<0.05)$.

\section{DISCUSSION}

The incidence of critical limb ischemia (CLI) is reported to be 10 per 10,000 population, with about $27 \%$ due to infragenicular disease ${ }^{(7)}$. Because of aging, persistently elevated levels of smoking, and the rapid increase in diabetes mellitus rates, the incidence of infragenicular disease continues to increase (13). Recently, a growing body of evidence highlighted promising results of infragenicular angioplasty in diabetic patients with CLI; it was shown that infragenicular angioplasty achieved high patency rates and limb salvage in diabetic patients, which were comparable to non-diabetic patients ${ }^{(14)}$. Nonetheless, limited data are available about the safety and efficacy of infragenicular angioplasty in limited-resource areas like Egypt. Accordingly, our study aims to examine the effectiveness and safety of infragenicular angioplasty in diabetic patients with critical limb ischemia.

Our findings showed an overall success rate of $85 \%$, which persists for six months in about $65 \%$ of the included patients. Regarding limb salvage, $75 \%$ of the patients had limb salvage after six months in the form of rest pain relief, minor ulcer healing, and tissue healing after debridement or minor amputation. A large metaanalysis on 6769 patients demonstrated the efficacy of angioplasty in managing infrapopliteal atherosclerotic lesions with an overall success rate (primary patency rate) of $91.1 \%{ }^{(10)}$. Tartaglia et al. ${ }^{(15)}$ conducted a retrospective study on 101 high-risk diabetic patients with CLI and reported that the primary patency was $67 \%$, while the secondary patency was $83 \%$. In terms of limb salvage rate and survival rate, it was $84 \%$ and $86 \%$, respectively. In 63 patients with CLI due to Infrapopliteal (IP) lesions, Park et al. ${ }^{(16)}$ identified the primary patency rate was $75 \%$ in 1 year, and the limb salvage rate was $91 \%$. Ferraresi et al. ${ }^{(17)}$ recorded a 97 percent survival rate and 91 percent limb salvage rate in 101 diabetic patients who presented with CLI and were treated with angioplasty. In contrast, Sadaghianloo and his colleagues reported a very low rate of primary and secondary patency after angioplasty, $13 \%$ and 32\%, respectively. They found a significant association between the length of the occlusion and the success of the technique. Moreover, they demonstrated that the number of patent arteries at the end of the procedure is significantly associated with the rate of success; the larger number of patent arteries, the higher is the success rate $^{(\mathbf{1 8 )}}$.

$\mathrm{Ni}$ and his colleagues ${ }^{(19)}$ reported that limb salvage rates were $75 \%$ at one year and reached $62 \%$ after 10 years. Compared to the Adam et al. ${ }^{(20)}$ and Iida et al. ${ }^{\text {(21) }}$ studies, the limb salvage rate was lower in our study and Ni's study. The different populations could explain the difference in findings between our study and both Adam et al. ${ }^{(20)}$ and Iida et al. ${ }^{(21)}$. Ni's study and our study targeted mainly diabetic patients, while the aforementioned studies have fewer patients with diabetes. According to the regression analysis, DM was significantly correlated with lower-limb salvage rate and survival rate, which is confirmed by the previous literature. The multivariate analysis of Ni $\boldsymbol{e t}$ al. demonstrated that DM was associated with a higher risk of major amputation OR 2.813, 95\% (1.719-4.604), $\mathrm{p}<0.001^{\left({ }^{(19)}\right.}$.

Ten years ago, the most favored technique for endovascular diseases was to seek a clear blood circulation anterograde in the most accessible artery. However, Peregrin et al. (22) reported complete revascularization in diabetic patients with CLI if one, two, or three vessels were patent again, resulting in 1year limb salvage of 73,80 , and 83 percent, respectively. In the case of multiple lesions on various arteries, it is recommended to target the angiosome-related artery to ensure maximum revascularization ${ }^{(23)}$. Nevertheless, it is often difficult, particularly in heavily calcified lesions in diabetic patients ${ }^{\text {(24). }}$.

Previous CLI research has mainly focused on patency and limb salvage rates, neglecting costeffectiveness, clinical improvement, and functional status ${ }^{(25)}$. The results of Romiti et $\boldsymbol{a l}$. ' $^{(\mathbf{2 6 )}}$ meta-analysis on 30 infrapopliteal angioplasty studies showed the futility of these endpoints and their ability to misinform patient outcomes. They observed a significant difference between secondary patency and limb salvage, showing that patency was not a requirement for avoiding amputation.

Regarding the safety of angioplasty, our findings showed that only $15 \%$ of the included patients had major amputation. To predict the risk of amputation, Ni et al. (19) developed a predicting score consist of age $<69$ years, DM, history of cerebral vascular disease, endstage renal disease, Rutherford classification, repeat intervention, number of straight-line flows. Another method was suggested by Suárez-Cuenca et al. ${ }^{\text {(27), who }}$ applied the Local Circulating Mononuclear Progenitor Cells to predict the amputation in angioplasty-treated patients with CLI. In terms of mortality, we did not record any case of death in this study; however, the mortality rate in the study of Ni et al. ${ }^{(\mathbf{1 9})}$ was $5.9 \%$. One patient in our study was reported with a large hematoma and underwent pseudo-aneurysm. In the study of Ni $\boldsymbol{e t}$ al. ${ }^{(19)}, 3 \%$ had vessel perforation, $2 \%$ had distal embolization, and $1 \%$ of the patients had a hematoma.

We acknowledge that this prospective study has some limitations. All patients were recruited from one center only; therefore, these results may not be generalized to all patients. In addition, the small sample size and the lack of long-term follow-up are other limitations.

In conclusion, infragenicular angioplasty exhibited efficacy in CLI management in diabetic patients, with an acceptable patency rate and safety 
profile. Nonetheless, the current published literature shows conflicting results, and further studies with multinational collaboration are required to assess the outcomes of infragenicular angioplasty.

\section{Financial support and sponsorship: Nil. \\ Conflict of Interest: Nil.}

\section{REFERENCES}

1. Pendsey S (2010): Understanding diabetic foot. Int $\mathbf{J}$ Diabetes Dev Ctries [Internet], 30(2):75-9.

2. Manickum P, Mashamba-Thompson T, Naidoo $\mathrm{R}$ et al. (2021): Knowledge and practice of diabetic foot care A scoping review. Diabetes Metab Syndr., 15(3):783-93.

3. Assaad-Khalil S, Zaki A, Abdel Rehim A et al. (2015): Prevalence of diabetic foot disorders and related risk factors among Egyptian subjects with diabetes. Prim Care Diabetes, 9(4):297-303.

4. Aysert Yıldız P, Özdil T, Dizbay M et al. (2018): Peripheral arterial disease increases the risk of multidrugresistant bacteria and amputation in diabetic foot infections. Turkish J Med Sci., 48(4):845-50.

5. Yuksel A, Velioglu Y, Cayir M et al. (2018): Current status of arterial revascularization for the treatment of critical limb ischemia in infrainguinal atherosclerotic disease. Int $\mathbf{J}$ Angiol Off Publ Int Coll Angiol Inc., 27(3):132-7.

6. Faries P, Teodorescu V, Morrissey $\mathbf{N}$ et al. (2004): The role of surgical revascularization in the management of diabetic foot wounds. Am J Surg., 187(5A):34-37.

7. Norgren L, Hiatt W, Dormandy J et al. (2007): Intersociety consensus for the management of peripheral arterial disease (TASC II). J Vasc Surg., 45: 5-67.

8. Shah D, Darling R, Chang B et al. (1995): Long-term results of in situ saphenous vein bypass. Analysis of 2058 cases. Ann Surg., 222(4):438-43.

9. Pursnani S, Korley F, Gopaul $\mathrm{R}$ et al. (2012): Percutaneous coronary intervention versus optimal medical therapy in stable coronary artery disease: a systematic review and meta-analysis of randomized clinical trials. Circ Cardiovasc Interv., 5(4):476-90.

10. Mustapha J, Finton S, Diaz-Sandoval L et al. (2016): Percutaneous transluminal angioplasty in patients with infrapopliteal arterial disease: Systematic Review and Meta-Analysis. Circ Cardiovasc Interv.,9(5):e003468.

11. Lipsky B, Berendt A, Deery $H$ et al. (2016): Diagnosis and treatment of diabetic foot infections. Vol. 117, Plastic and Reconstructive Surgery. Plast Reconstr Surg., 6: 1523.

12. Rutherford R, Baker J, Ernst C et al. (1997): Recommended standards for reports dealing with lower extremity ischemia: Revised version. Journal of Vascular Surgery, 26: 517-38.

13. Corriere M, Rooparinesingh N, Kalyani R (2013): Epidemiology of diabetes and diabetes complications in the elderly: an emerging public health burden. Curr Diab Rep [Internet], 13(6):805-13.

14. Gamal W, Mohammed Askary Z, Ibrahim M (2017):
Comparison of clinical outcomes of infragenicular angioplasty between diabetic and non-diabetic patients with peripheral arterial occlusive disease. Angiol Open Access., 05(03): 130-136.

15. Tartaglia E, Lejay A, Georg Y et al. (2016): Results of isolated infrapopliteal percutaneous transluminal angioplasty for critical limb ischemia in high-risk diabetic patients. Vascular, 24(5):515-22.

16. Park S, Kim J, Yun I et al. (2013): Clinical outcomes of endovascular treatments for critical limb ischemia with chronic total occlusive lesions limited to below-the-knee arteries. Acta Radiol., 54: 785-789.

17. Ferraresi R, Centola M, Ferlini M et al. (2009): Longterm outcomes after angioplasty of isolated, below-theknee arteries in diabetic patients with critical limb ischaemia. Eur J Vasc Endovasc Surg., 37: 336-42.

18. Sadaghianloo $\mathrm{N}$, Jean-Baptiste $\mathrm{E}$, Declemy $\mathrm{S}$ et al. (2013): Percutaneous angioplasty of long tibial occlusions in critical limb ischemia. Ann Vasc Surg., 27(7):894-903.

19. Ni W, Leong S, Irani F et al. (2020): Angioplasty-first" approach for limb salvage in asian patients with critical limb ischemia: Outcomes from 3,303 angioplasties on 2,402 limbs in a single tertiary hospital. J Vasc Interv Radiol., 31(12):1969-1977.

20. Adam D, Beard J, Cleveland T et al. (2005): Bypass versus angioplasty in severe ischaemia of the leg (BASIL): multicentre, randomised controlled trial. Lancet (London, England), 366(9501):1925-34.

21. Iida O, Nakamura $M$, Yamauchi Y et al. (2013): Endovascular treatment for infrainguinal vessels in patients with critical limb ischemia: OLIVE registry, a prospective, multicenter study in Japan with 12-month follow-up. Circ Cardiovasc Interv., 6(1):68-76.

22. Peregrin J, Kožnar B, Kováč J et al. (2010): PTA of infrapopliteal arteries: Long-term clinical follow-up and analysis of factors influencing clinical outcome. Cardiovasc Intervent Radiol., 33: 720-5.

23. Taylor G, Pan W (1998): Angiosomes of the leg: Anatomic study and clinical implications. Plast Reconstr Surg., 102: 599-616.

24. Pernès J, Auguste $M$, Borie $H$ et al. (2015): Infrapopliteal arterial recanalization: A true advance for limb salvage in diabetics. Diagnostic and Interventional Imaging, 546: 1-12.

25. Sultan S, Tawfick W, Hynes N (2013): Cool excimer laser-assisted angioplasty (CELA) and tibial balloon angioplasty (TBA) in management of infragenicular arterial occlusion in critical lower limb ischemia (CLI). Vasc Endovascular Surg., 47(3):179-91.

26. Romiti M, Albers M, Brochado-Neto F et al. (2008): Meta-analysis of infrapopliteal angioplasty for chronic critical limb ischemia. J Vasc Surg., 47(5):975-981.

Suárez-Cuenca J, Vera-Gómez E, Hernández-Patricio A et al. (2020): Predicting Amputation using Local Circulating Mononuclear Progenitor Cells in Angioplasty-treated Patients with Critical Limb Ischemia. J Vis Exp., (163): e61503. 